\title{
CONSIDERATIONS FOR SOUTH AFRICAN HIGHER EDUCATION: A 'NATIONAL STUDENT MEN WHO HAVE SEX WITH MEN' SEXUAL BEHAVIOUR SURVEY
}

\author{
J. G. Brink \\ Equality Unit \\ Stellenbosch University \\ Stellenbosch, South Africa \\ e-mail: jgbrink@sun.ac.za
}

\section{ABSTRACT}

This non-experimental study contributes to the quantitative knowledge about university student men who have sex with men (MSM), their sexual behaviour and their experiences on campus. A sample of 8896 students (MSM $n=896$; non-MSM $n=7973$ ) were recruited through convenience sampling in a once off online survey at fourteen higher education institutions (HEIs) in South Africa. The results indicate various risk factors for HIV transmission. These include: high partner turnover, concurrent sexual partners, presence of sexually transmitted infections, early sexual debut, having female sex partners, forced sex experiences, and inconsistent condom usage. MSM were found to have statistically higher levels of alcohol and drug use than non-MSM students. Student MSM in South African HEIs engage in sexual behaviours which elevates their risk of contracting HIV and other sexually transmitted infections. Student MSM also experience abuse or violence on campus due to their sexual preferences.

Keywords: men who have sex with men, university students, higher education, sexual health, sexual behaviour, alcohol and drug use, HIVIAids

\section{INTRODUCTION}

MSM represent a wide array of behaviours, worldviews and ways of engaging with their sexuality. A limiting definition of MSM may fail to recognise their understandings of themselves (WHO 2004) and may exacerbate social discrimination and constrain access to human immunodeficiency virus (HIV) services. Not all MSM think about their behaviours as explicitly sexual. It may be counter-productive to impose a sexual definition onto acts which may be understood in different ways by these men (WHO 2004).

Homophobia is a form of social discrimination, which can be defined as 'mean, unfair or unequal treatment intended to marginalise or subordinate individuals or communities based on their real or perceived affiliation with socially constructed stigmatised attributes' (Ayala et al. 2010, 2). Research on stress has shown that the expectation of discrimination and the actual 
experience of discrimination contribute independently and collectively to sub-optimal mental health (Meyer 1995).

Many societies place a social premium on the traditional heterosexual family and the resulting expectations of marriage and producing children place great pressure on MSM (Adimora, Schoenbach and Doherty 2007). When MSM succumb to heterosexual marriage, they often maintain secret sexual relationships with men, resulting in multiple opportunities for HIV transmission (Adimora, Schoenbach and Doherty 2007).

There have been key improvements in the health and well-being of MSM living with HIV in high income countries in the northern hemisphere (Hart and Elford 2010). This is not the case in most parts of the world. There are currently nearly 80 countries which criminalise same-sex practices between consenting adults (MSMGF 2008). Due to demographic and cultural differences, it is necessary to design HIV prevention interventions for MSM that are suited to the specific context and culture. The appreciation of differences in behaviour among MSM is essential to the success of HIV prevention interventions (CDC 2007). Alternative HIV prevention behaviours have emerged among MSM, including sero-sorting of sexual partners and strategic positioning (CDC 2007; Hart and Elford 2010).

Various studies have explored sexual risk behaviour among MSM who are young (Bolding et al. 2007; Dudley et al. 2004; MacKellar et al. 1996; Salomon et al. 2009; Warren et al. 2008), attending high school (Berten and Van Rossem 2009; Faulkner and Cranston 1998), or attending college or university (Brown and Vanable 2007; Cong et al. 2008; Eisenberg 2001; Lindley et al. 2003; So, Wong, and DeLeon 2005; Tung, Ding, and Farmer 2008).

Findings suggest that risky sexual behaviour places many of these young MSM at an elevated risk of contracting HIV. Factors contributing to this greater risk are: unprotected anal intercourse, high partner turnover, the presence of sexually transmitted infections (STI), unknown HIV status in a context of high HIV prevalence, complacency about risk, use of the internet in identifying partners, social discrimination, the presence of female sexual partners, alcohol use before sex, and the use of drugs for recreational purposes (Benotsch, Kalichman and Cage 2001; Brown and Vanable 2007; Eisenberg 2001; Lindley et al. 2003; So et al. 2005).

Research has indicated that there is often a culture of secrecy in Africa where the distinction between heterosexuality and same-sex behaviour is often less clear than in the West (Murray and Roscoe 1998). These authors suggest that social expectations in Africa do not require an individual to suppress same-sex desires or behaviour but these desires should not surpass or displace procreation. It is important, therefore, to better understand the scope of male same-sex behaviours among students, specifically in an African context. A key question is whether African 
social expectations about same-sex behaviours predispose student MSM to sexual risk-taking in an environment of high HIV prevalence.

A literature review on MSM at HEIs in South Africa yielded very limited information about this potentially at-risk group and their sexual behaviours. The first national knowledge, attitude, behaviour and prevalence study at HEIs found that 6 per cent of male students reported same-sex practices and that HIV prevalence among student MSM (4.1\%) was more than twice the rate for heterosexual male students (HEAIDS 2010). The study lacked detailed data on MSM behaviour, HIV knowledge, attitudes to sex and experiences of social homophobia at HEIs. HEAIDS (2010) recommended that HEI management and other institutional structures should be proactive in ensuring that the rights of MSM are protected.

There are indications that health promotion programmes created with a heterosexual audience in mind may be misdirected, awkward, inappropriate, and even harmful for male students who engage in same-sex sexual behaviours (Eisenberg 2001). Studies reflect the inadequacy of promotion of safer-sex practices to university students (Bouldrey, cited in Eisenberg 2001).

The aim of the study was to determine the potential for interventions which can strengthen services to LGBTQI and MSM students in South Africa with a view to create an enabling campus environment and a decline in new HIV cases among MSM. The two main objectives were to determine the extent of risky sexual behaviour in a sample of student MSM at South African universities, secondly, to determine the extent of alcohol and drug use among these students by means of an online survey, and finally to better understand experiences of violence and/or abuse on campus among MSM.

\section{METODOLOGY}

\section{Study design}

The research was cross-sectional in design and registered university students from the 14 selected HEIs were invited to participate in the study through their institutions. The questionnaire was self-administered via an online survey in most cases. However some HEIs also used paper-based surveys, and the responses were subsequently entered into the online tool.

The questionnaires contained questions relating to demographic and socio-economic factors as well as personal experiences and behaviours. The survey instrument consisted of a set of questionnaires which were all completed at the same time by participants. The data for MSM and non-MSM students were then split into two groups. 


\section{Participants and procedures}

All aspects of the study were conducted in accordance with Stellenbosch University (SU) guidelines on research ethics as well as the ethical guidelines and principles of the International Declaration of Helsinki, South African Guidelines for Good Clinical Practice and the Medical Research Council Ethical Guidelines for Research. The study was approved by the Research Ethics Committee (Human Research, non-medical) at SU. Confidentiality was guaranteed by ensuring that no personal identifiers were collected and that the survey link could not be traced back to participants' email accounts. No incentives were given to the participants and referral contact numbers to relevant support services were provided in case the sensitive nature of some of the questions caused discomfort.

\section{MEASURES}

The survey instrument consisted of a set of questionnaires which were all completed at the same time by participants.

\section{Sexual behaviour history questionnaire}

This questionnaire allowed for self-reporting on sexual behaviour. It was developed by Bryan, Kagee and Broaddus (2006) and adapted by the researchers at SU in consultation with various experts and practitioners at various HEIs.

\section{Alcohol and other drug abuse questionnaire (AODQ)}

The AODQ questionnaire was developed by the Centre for Substance Abuse Treatment (Winters and Zenilman 1994). The summed score for each participant was used to determine their alcohol and drug use score.

\section{RESULTS}

\section{Demographic characteristics}

The number of MSM who volunteered for the survey, as a proportion of the total sample, varied by HEI, from 4.7 per cent at the lower end to 26.3 per cent at the upper end. The participating HEIs were: Central University of Technology, Durban University of Technology, Mangosuthu University of Technology, Nelson Mandela Metropolitan University, Stellenbosch University, Tshwane University of Technology, University of Cape Town, University of KwaZulu-Natal, 
University of Limpopo, University of South Africa, University of the Free State, University of the Western Cape, University of Venda and Walter Sisulu University.

Table 1: Participation in survey per HEI

\begin{tabular}{|l|c|c|c|c|c|}
\hline \multirow{2}{*}{ Name of HEI } & \multicolumn{2}{c|}{ MSM } & \multicolumn{2}{c|}{ Non-MSM } & All participants \\
\cline { 2 - 6 } & $\mathbf{n}$ & $\%$ & $\mathbf{n}$ & N & 208 \\
\hline Central University of Technology & 41 & 19.7 & 167 & 80.3 & 797 \\
\hline Durban University of Technology & 81 & 10.2 & 716 & 89.8 & 640 \\
\hline Mangosuthu University of Technology & 118 & 18.4 & 522 & 81.6 & 831 \\
\hline Nelson Mandela Metropolitan University & 84 & 10.1 & 747 & 89.9 & 1014 \\
\hline Stellenbosch University & 116 & 11.4 & 898 & 88.6 & 47 \\
\hline Tshwane University of Technology & 4 & 8.5 & 43 & 91.5 & 1543 \\
\hline University of Cape Town & 137 & 8.9 & 1406 & 91.1 & 311 \\
\hline University of KwaZulu-Natal & 33 & 10.6 & 278 & 89.4 & 285 \\
\hline University of Limpopo & 46 & 16.1 & 239 & 83.9 & 1151 \\
\hline University of South Africa & 109 & 9.5 & 1042 & 90.5 & 491 \\
\hline University of the Free State & 23 & 4.7 & 468 & 95.3 & 1100 \\
\hline University of the Western Cape & 63 & 5.7 & 1037 & 94.3 & 19 \\
\hline University of Venda & 5 & 26.3 & 14 & 73.7 & 432 \\
\hline Walter Sisulu University & 36 & 8.3 & 396 & 91.7 & \\
\hline
\end{tabular}

The sample size including all MSM $(\mathrm{n}=896)$ and non-MSM $(\mathrm{n}=7973)$ was substantial $(\mathrm{n}=$ 8869). Of the total group of 869 MSM participants, 61 per cent were black students, 20 per cent were white, 12 per cent coloured and 2.7 per cent of Indian origin. In addition, 1.3 per cent said they belonged to 'other' groups and 3.7 per cent chose not to answer this question. Almost nine out of ten participants in the MSM sample (84.5\%) were undergraduate students, with 34.3 per cent in their first academic year and 23.1 per cent in their second academic year. Of the student MSM, 4.6 per cent indicated that they had children and 4.6 per cent were married. Less than half (42.1\%) of the student MSM sample reported living in a university residence, while a third (30.7\%) lived in accommodation other than a family home or a university residence. Just over half of the student MSM were full-time students (53.5\%) and 23.9 per cent reported that they had some form of employment. In the student MSM sample, 71.2 per cent self-identified as homosexual, 20 per cent reported being bisexual, 7.4 per cent heterosexual and 1.5 per cent identified themselves with another sexual orientation. One-third of MSM reported not knowing any person living with HIV, while 30.2 per cent reported knowing one or two people living with the virus, while a further 18.6 per cent said they knew between three and five people with HIV. One in ten student MSM (10.2\%) had missed university classes to attend a funeral of someone who had died from AIDS-related causes. More than 90 per cent of student MSM reported using social media (Facebook, Twitter, Google+, Instagram etc.) on a weekly basis. 
Table 2: Demographic characteristics of the sample

\begin{tabular}{|c|c|c|c|}
\hline \multirow[t]{2}{*}{ Questions } & \multirow[t]{2}{*}{ Possible answers } & \multicolumn{2}{|c|}{$\begin{array}{c}\text { MSM } \\
\text { participants }\end{array}$} \\
\hline & & $\mathbf{n}$ & $\%$ \\
\hline \multirow[t]{2}{*}{ Are you a South African citizen? } & Yes & 845 & 94.3 \\
\hline & No & 51 & 5.7 \\
\hline \multirow[t]{3}{*}{ What is your biological sex? } & Female & 0 & 0.0 \\
\hline & Intersex & 0 & 0.0 \\
\hline & Male & 896 & 100.0 \\
\hline \multirow[t]{2}{*}{ Are you currently employed } & Yes & 214 & 23.9 \\
\hline & No & 682 & 76.1 \\
\hline \multirow[t]{2}{*}{ If yes, part-time or full-time? } & Part-time & 106 & 46.5 \\
\hline & Full-time & 122 & 53.5 \\
\hline \multirow[t]{2}{*}{ Do you have any children? } & Yes & 95 & 10.6 \\
\hline & No & 801 & 89.4 \\
\hline \multirow[t]{2}{*}{ Are you married? } & Yes & 41 & 4.6 \\
\hline & No & 855 & 95.4 \\
\hline \multirow[t]{2}{*}{ Are you undergraduate or post-graduate? } & Undergraduate & 757 & 84.5 \\
\hline & Post-graduate & 139 & 15.5 \\
\hline \multirow[t]{3}{*}{ Where do you live while at university? } & University residence & 377 & 42.1 \\
\hline & With my family & 244 & 27.2 \\
\hline & Other accommodation & 275 & 30.7 \\
\hline \multirow{7}{*}{$\begin{array}{l}\text { What is the highest level of education in your } \\
\text { family? }\end{array}$} & Did not finish high school & 52 & 5.8 \\
\hline & Finished high school & 265 & 29.6 \\
\hline & Some university education & 127 & 14.2 \\
\hline & Undergraduate university degree & 135 & 15.1 \\
\hline & Some postgraduate education & 55 & 6.1 \\
\hline & Post-graduate degree & 213 & 23.8 \\
\hline & I don't know & 49 & 5.5 \\
\hline \multirow{5}{*}{$\begin{array}{l}\text { How many people with HIVIAIDS have you ever } \\
\text { known? }\end{array}$} & None & 296 & 33.0 \\
\hline & $1-2$ & 271 & 30.2 \\
\hline & $3-5$ & 167 & 18.6 \\
\hline & $6-10$ & 67 & 7.5 \\
\hline & 11 or more & 95 & 10.6 \\
\hline \multirow{2}{*}{$\begin{array}{l}\text { Have you missed classes to attend a funeral of } \\
\text { a person who died of AIDS-related diseases? }\end{array}$} & Yes & 91 & 10.2 \\
\hline & No & 805 & 89.8 \\
\hline \multirow[t]{2}{*}{ Do you use social media on a weekly basis? } & Yes & 833 & 93.0 \\
\hline & No & 63 & 7.0 \\
\hline
\end{tabular}

\section{Lifetime sexual behaviour}

The vast majority of student MSM (85\%) reported at least one penetrative sexual encounter prior to taking part in the survey. Many of the 760 sexually active MSM reported experience of more than one type of sex act (anal, oral and/or vaginal sex). Of the total number of positive responses by MSM to all three types of sex, penetrative anal sex accounted for 38 per cent, oral sex for 34 per cent and penetrative vaginal sex for 28 per cent.

A total of 24.4 per cent of the MSM sample and 15.9 per cent of the non-MSM sample had their first sexual experience before the age of 16 years. A high proportion (42.4\% of MSM and 48.1\% of non-MSM) were in the 16-18 years of age group when they first had sex, and 21.3 per cent of MSM (24.0\% of non-MSM) first had sex when they were between 19 or 20 years of age. 
Table 3: Reported sexual behaviours of MSM and non-MSM students

\begin{tabular}{|c|c|c|c|c|c|}
\hline \multirow{2}{*}{ Questions } & \multirow{2}{*}{$\begin{array}{l}\text { Possible } \\
\text { answers }\end{array}$} & \multicolumn{2}{|c|}{ MSM } & \multicolumn{2}{|c|}{ Non-MSM } \\
\hline & & $\mathbf{n}$ & $\%$ & $\mathbf{n}$ & $\%$ \\
\hline \multirow[t]{2}{*}{ Have you ever had sexual intercourse? } & Yes & 760 & 85.0 & 5417 & 68.1 \\
\hline & No & 134 & 15.0 & 2534 & 31.9 \\
\hline \multirow{2}{*}{$\begin{array}{l}\text { Are you currently in a relationship with a primary } \\
\text { partner? }\end{array}$} & Yes & 431 & 56.6 & 3656 & 67.3 \\
\hline & No & 331 & 43.4 & 1773 & 32.7 \\
\hline \multirow[t]{3}{*}{ Do you have sex with your primary partner? } & Yes & 415 & 54.5 & 3519 & 64.8 \\
\hline & No & 99 & 13.0 & 572 & 10.5 \\
\hline & Does not apply & 248 & 32.5 & 1338 & 24.7 \\
\hline \multirow{3}{*}{$\begin{array}{l}\text { Do you have a steady non-primary partner you } \\
\text { have sex with? }\end{array}$} & Yes & 270 & 35.4 & 1209 & 22.3 \\
\hline & No & 399 & 52.4 & 3480 & 64.1 \\
\hline & Does not apply & 93 & 12.2 & 740 & 13.6 \\
\hline \multirow{3}{*}{$\begin{array}{l}\text { Do you have a non-steady partner you have sex } \\
\text { with? }\end{array}$} & Yes & 278 & 36.5 & 1238 & 22.8 \\
\hline & No & 386 & 50.7 & 3428 & 63.1 \\
\hline & Does not apply & 98 & 12.9 & 763 & 14.1 \\
\hline \multirow[t]{2}{*}{ What form of sex have you had - anal sex? } & Yes & 358 & 40.0 & 811 & 10.2 \\
\hline & No & 538 & 60.0 & 162 & 89.8 \\
\hline \multirow[t]{2}{*}{ What form of sex have you had - oral sex? } & Yes & 444 & 49.6 & 3301 & 41.4 \\
\hline & No & 452 & 50.4 & 4672 & 58.6 \\
\hline \multirow[t]{2}{*}{ What form of sex have you had - vaginal sex? } & Yes & 495 & 55.2 & 5107 & 64.1 \\
\hline & No & 401 & 44.8 & 2866 & 35.9 \\
\hline
\end{tabular}

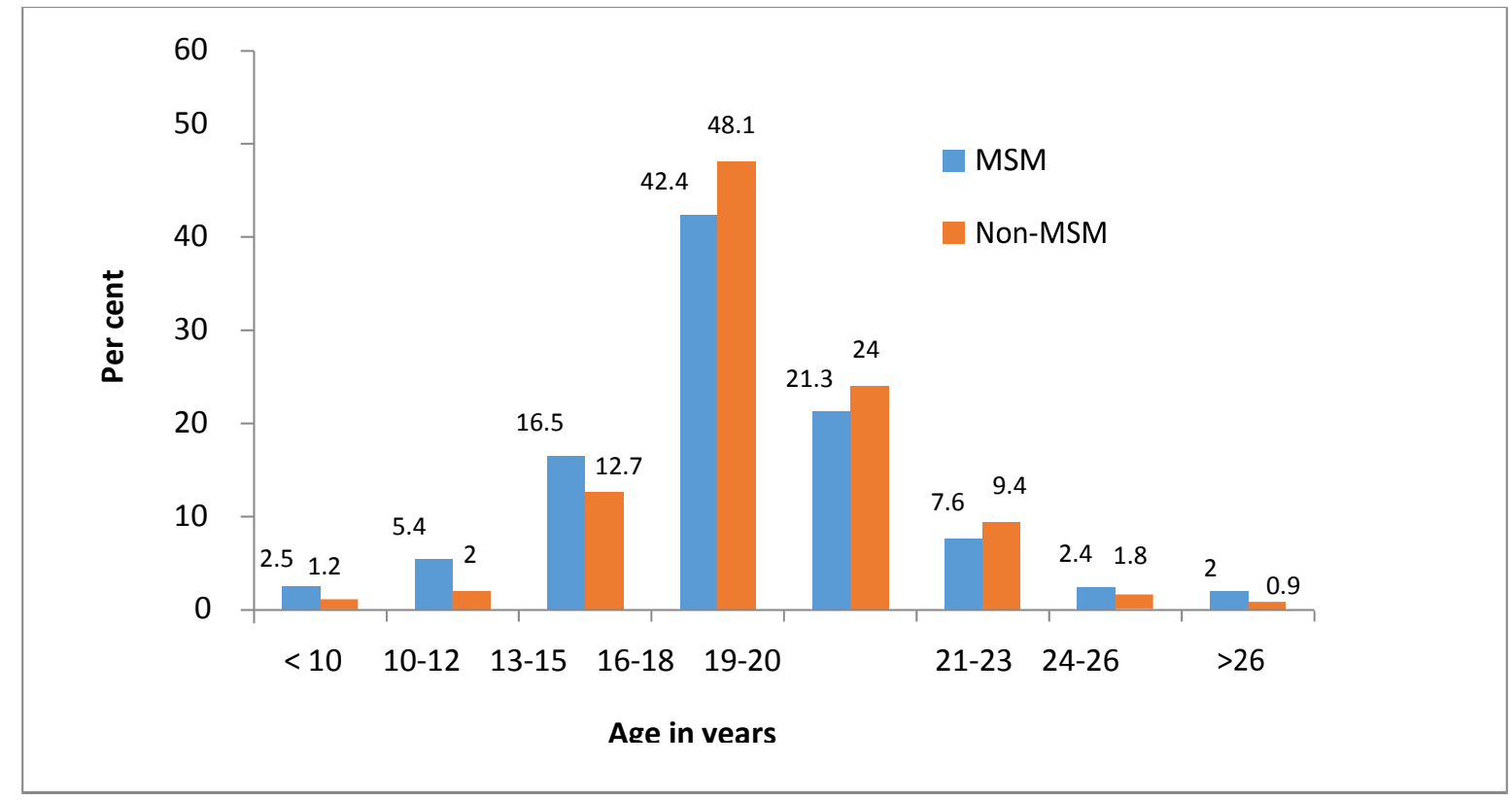

Figure 1: Age of sexual debut of MSM and non-MSM participants

\section{Sexual behaviour in past year}

Among student MSM, 54.5 per cent reported having had at least one female sex partner in the past year and 47.9 per cent reported having had at least one male sex partner in the same period. One out of five sexually active MSM in the study (21.3\%) reported having had only one male sex partner in the past year, while 13.9 per cent had between two and three sex partners and 12.7 per cent reported having four or more sex partners. Almost 5 per cent of sexually active student MSM 
$(4.1 \%, n=31)$ reported more than nine male sex partners in the preceding year.

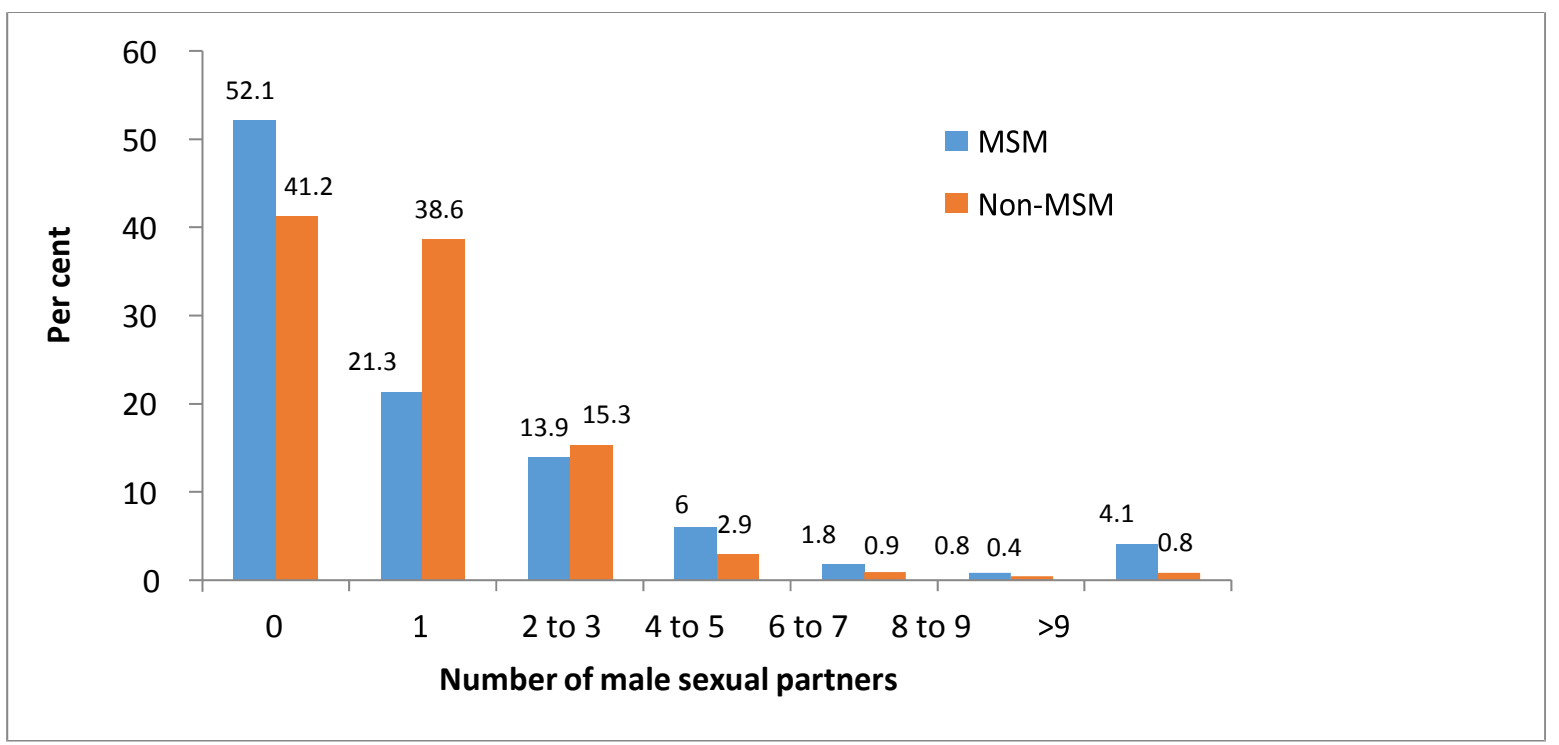

Figure 2: Reported number of male sexual partners in past year for MSM and non-MSM students

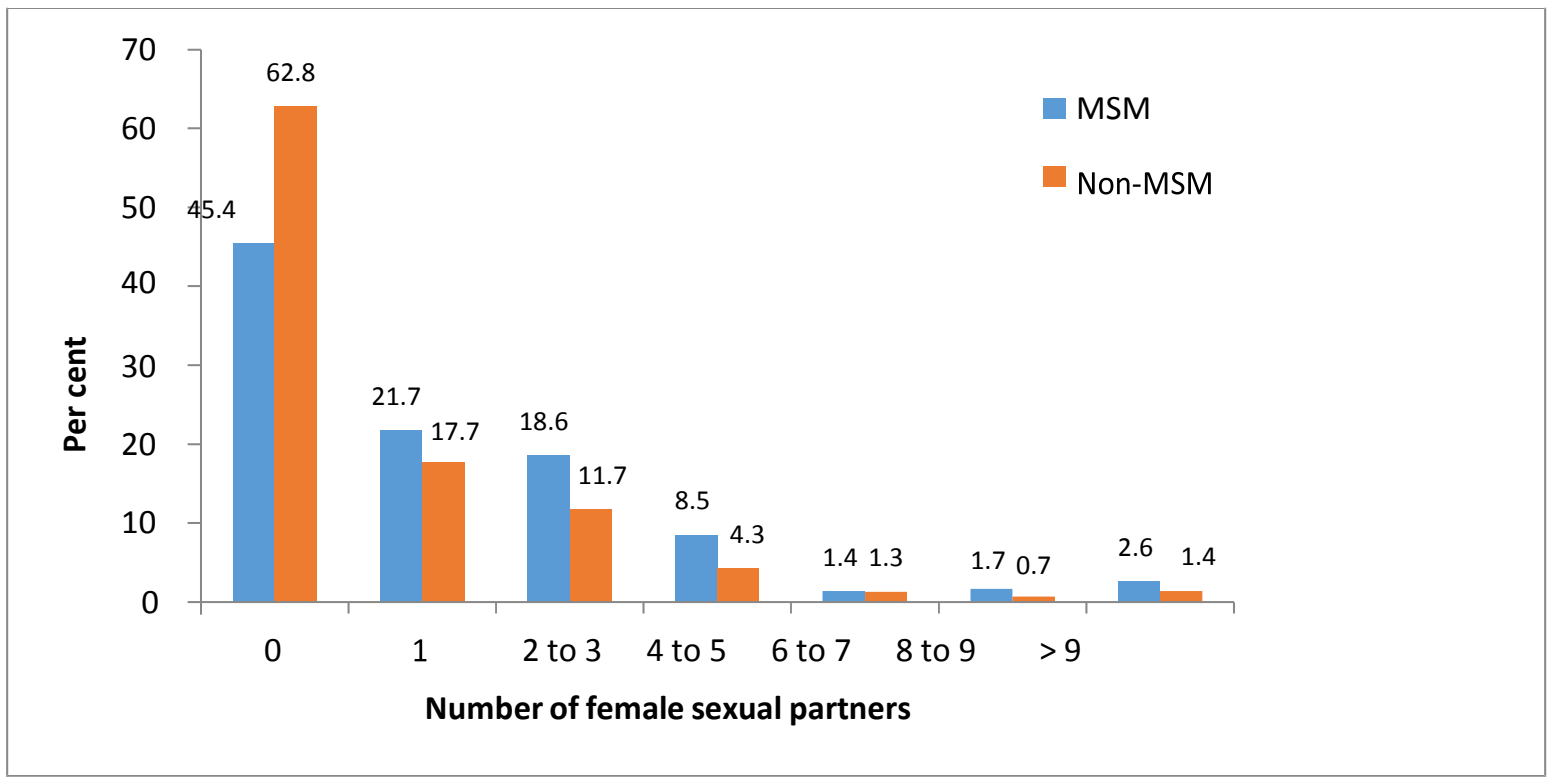

Figure 3: Reported number of female sexual partners in past year for MSM and non-MSM students

While the majority of MSM and non-MSM participants had not had concurrent partners in the year preceding the survey, about a quarter (23.9\%) of the MSM group reported having had one concurrent partner in this period while 17.1 per cent reported more than one concurrent partner in that year.

One-third (32.4\%) of student MSM reported having had penetrative anal sex without the use of condoms at least once in the past 12 months and 37.9 per cent of MSM reported having 
had penetrative vaginal sex without the use of condoms during the past year. One-third of MSM (31.1\%) reported having had oral sex with semen in their mouths and 44.5 per cent had had oral sex without semen in their mouths in the last year.

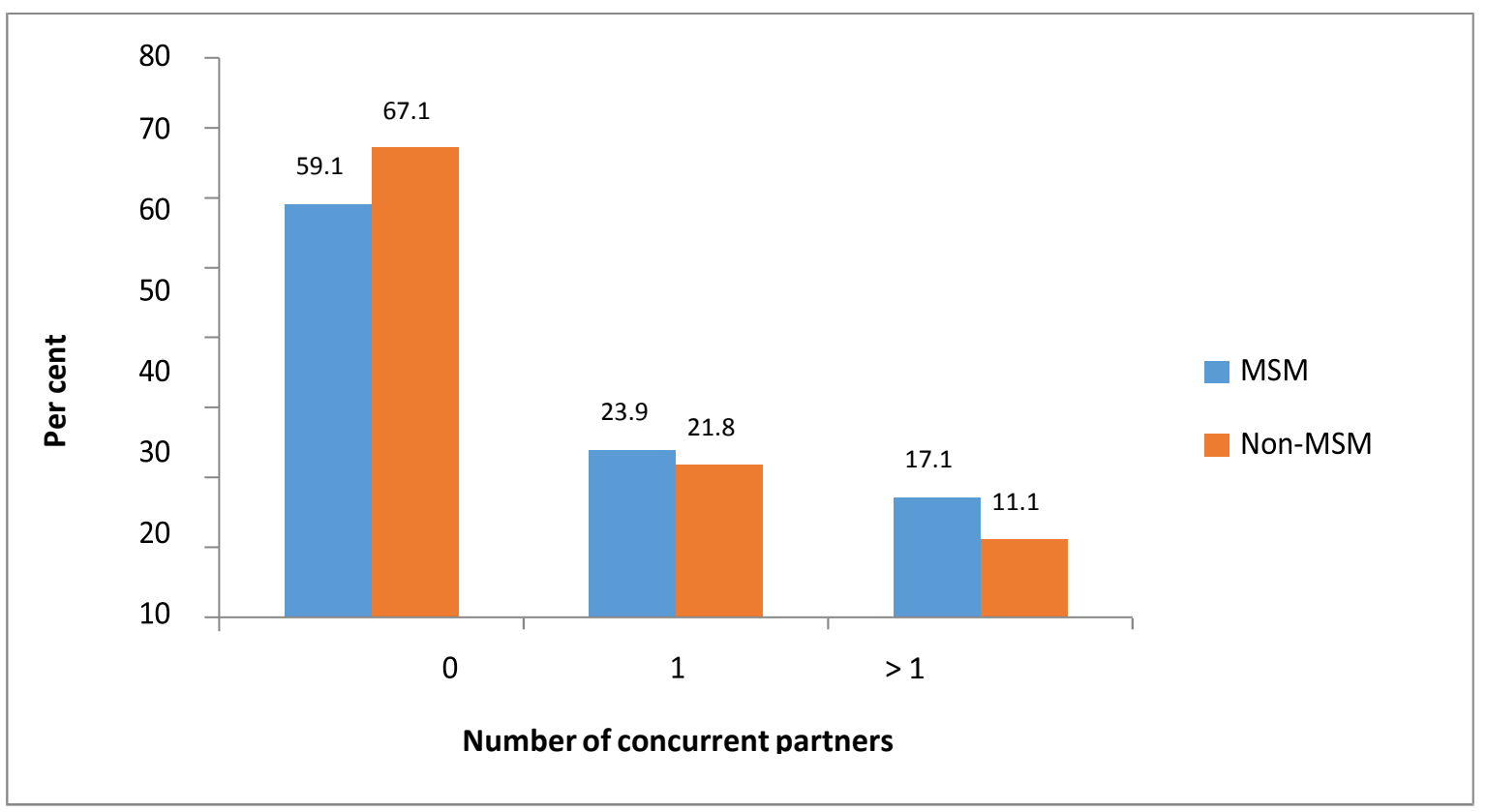

Figure 4: Number of concurrent sexual partners in past year for MSM and non-MSM students

Table 4: Reported condom use and exposure to risk of HIV infection

\begin{tabular}{|c|c|c|c|}
\hline \multirow[b]{2}{*}{ Questions } & \multirow[b]{2}{*}{ Possible answers } & \multicolumn{2}{|c|}{ MSM } \\
\hline & & $n$ & $\%$ \\
\hline \multirow{8}{*}{$\begin{array}{l}\text { How many times have you had anal sex with use of condoms in the } \\
\text { past } 12 \text { months? }\end{array}$} & 0 & 479 & 62.9 \\
\hline & $1-2$ & 92 & 12.1 \\
\hline & $3-5$ & 65 & 8.5 \\
\hline & $6-10$ & 45 & 5.9 \\
\hline & $11-20$ & 33 & 4.3 \\
\hline & $21-30$ & 16 & 2.1 \\
\hline & $31-40$ & 7 & 0.9 \\
\hline & $>40$ & 25 & 3.3 \\
\hline \multirow{8}{*}{$\begin{array}{l}\text { How many times have you had vaginal sex without use of condoms } \\
\text { in the past } 12 \text { months? }\end{array}$} & 0 & 473 & 62.1 \\
\hline & $1-2$ & 103 & 13.5 \\
\hline & $3-5$ & 70 & 9.2 \\
\hline & $6-10$ & 34 & 4.5 \\
\hline & $11-20$ & 20 & 2.6 \\
\hline & $21-30$ & 16 & 2.1 \\
\hline & $31-40$ & 7 & 0.9 \\
\hline & $>40$ & 39 & 5.1 \\
\hline \multirow{8}{*}{$\begin{array}{l}\text { How many times have you had vaginal sex with the use of condoms } \\
\text { in the past } 12 \text { months? }\end{array}$} & 0 & 404 & 53 \\
\hline & $1-2$ & 102 & 13.4 \\
\hline & $3-5$ & 70 & 9.2 \\
\hline & $6-10$ & 68 & 8.9 \\
\hline & $11-20$ & 50 & 6.6 \\
\hline & $21-30$ & 21 & 2.8 \\
\hline & $31-40$ & 7 & 0.9 \\
\hline & $>40$ & 40 & 5.2 \\
\hline
\end{tabular}




\begin{tabular}{|c|c|c|c|}
\hline \multirow[b]{2}{*}{ Questions } & \multirow[b]{2}{*}{ Possible answers } & \multicolumn{2}{|c|}{ MSM } \\
\hline & & $n$ & $\%$ \\
\hline \multirow{8}{*}{$\begin{array}{l}\text { How many times have you had sex with blood present in the } \\
\text { past } 12 \text { months? }\end{array}$} & 0 & 611 & 80.2 \\
\hline & $1-2$ & 108 & 14.2 \\
\hline & $3-5$ & 21 & 2.8 \\
\hline & $6-10$ & 14 & 1.8 \\
\hline & $11-20$ & 6 & 0.8 \\
\hline & $21-30$ & 0 & 0.0 \\
\hline & $31-40$ & 0 & 0.0 \\
\hline & $>40$ & 2 & 0.3 \\
\hline \multirow{8}{*}{$\begin{array}{l}\text { How many times have you had oral sex with semen in your mouth in } \\
\text { the past } 12 \text { months? }\end{array}$} & 0 & 525 & 68.9 \\
\hline & $1-2$ & 105 & 13.8 \\
\hline & $3-5$ & 50 & 6.6 \\
\hline & $6-10$ & 24 & 3.1 \\
\hline & $11-20$ & 28 & 3.7 \\
\hline & $21-30$ & 13 & 1.7 \\
\hline & $31-40$ & 5 & 0.7 \\
\hline & $>40$ & 12 & 1.6 \\
\hline \multirow{8}{*}{$\begin{array}{l}\text { How many times have you had oral sex without semen in your } \\
\text { mouth in the past } 12 \text { months? }\end{array}$} & 0 & 423 & 55.5 \\
\hline & $1-2$ & 116 & 15.2 \\
\hline & $3-5$ & 67 & 8.8 \\
\hline & $6-10$ & 59 & 7.7 \\
\hline & $11-20$ & 33 & 4.3 \\
\hline & $21-30$ & 19 & 2.5 \\
\hline & $31-40$ & 15 & 2.0 \\
\hline & $>40$ & 30 & 3.9 \\
\hline
\end{tabular}

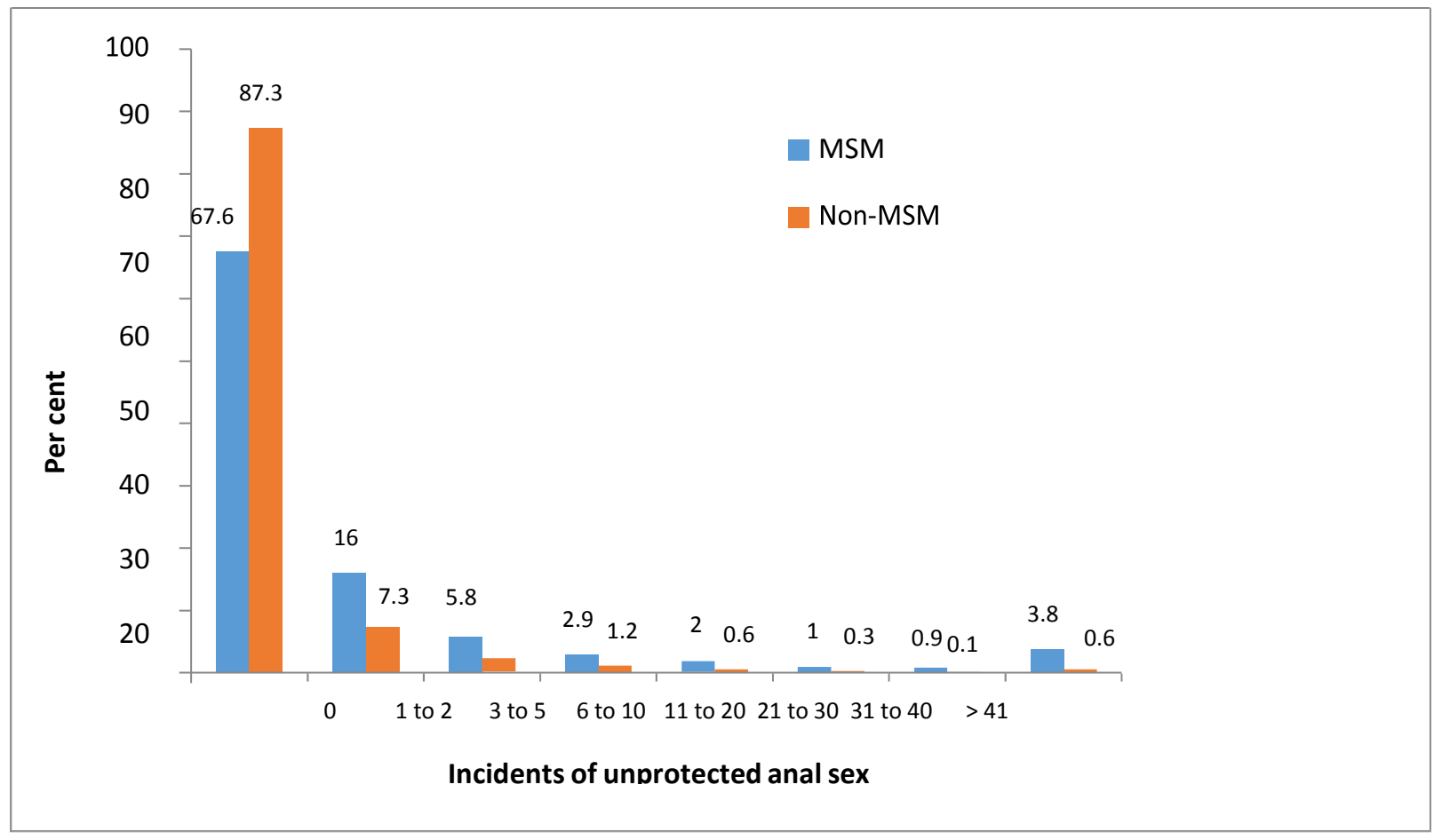

Figure 5: Reported incidents of unprotected anal sex in past year for MSM and non-MSM students

Two-thirds (63.4\%) of the MSM participants reported having used condoms the last time they had penetrative sex. More than a third (36.6\%) reported they had not used condoms during their last sexual encounter, implying that they use condoms inconsistently or not at all. Four out of ten 
reported using lubricant the last time they had penetrative sex. Only a third of MSM (28.9\%) reported that free lubricant sachets were available at their HEI, whereas free condoms were much more freely available (87.9\%). MSM preference for brand of condom used was as follows: Durex: 28.5 per cent, Lovers Plus: 25.4 per cent, Choice: 23 per cent, and other condom brands: 22.2 per cent.

Only 1.9 per cent reported using a female condom the last time they had sex. One-third of MSM (34.3\%) stated that they used condoms 'all of the time' when having sex while another third (31.9\%) said they used condoms 'most of the time'.

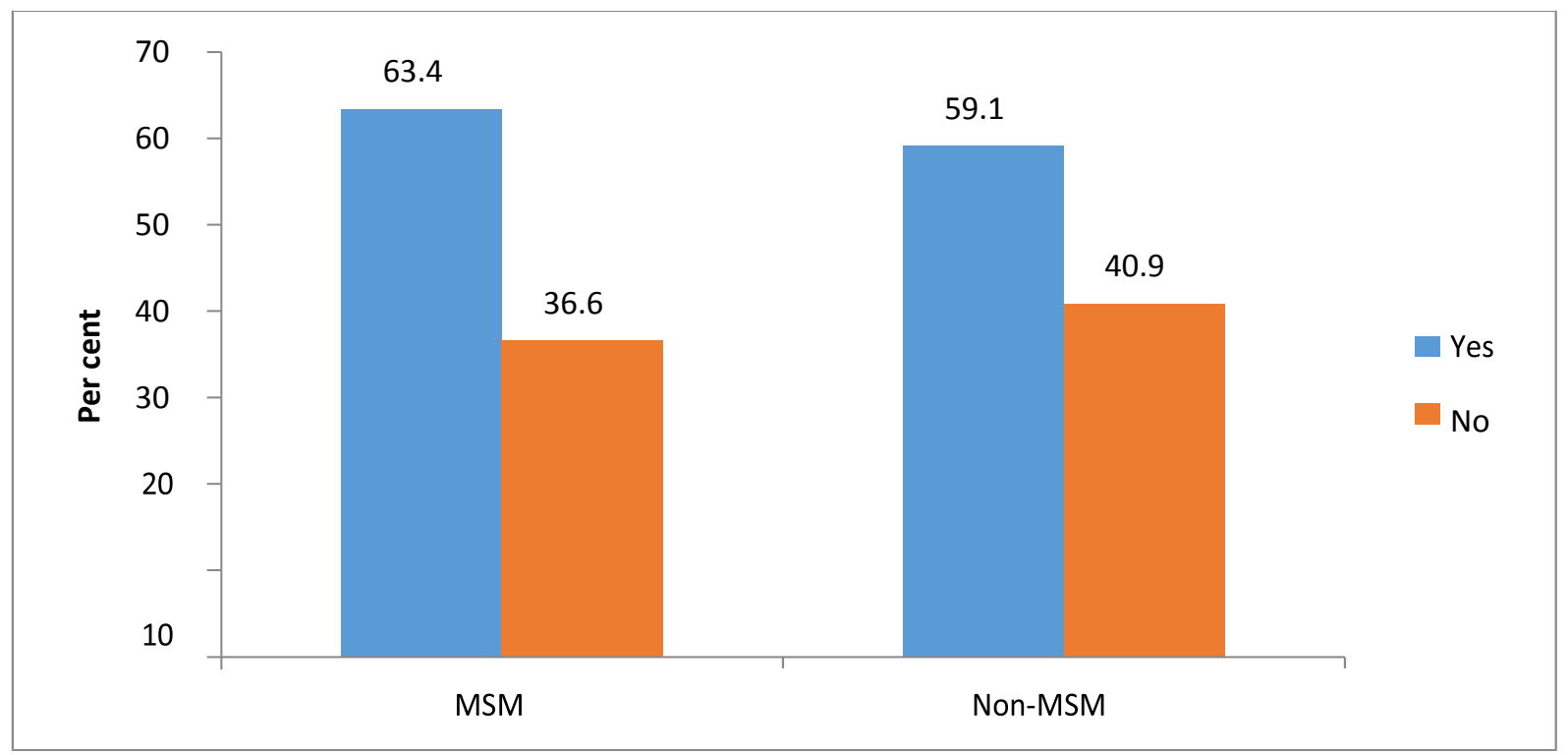

Figure 6: Condom use by participants during last sex act for MSM and non-MSM students

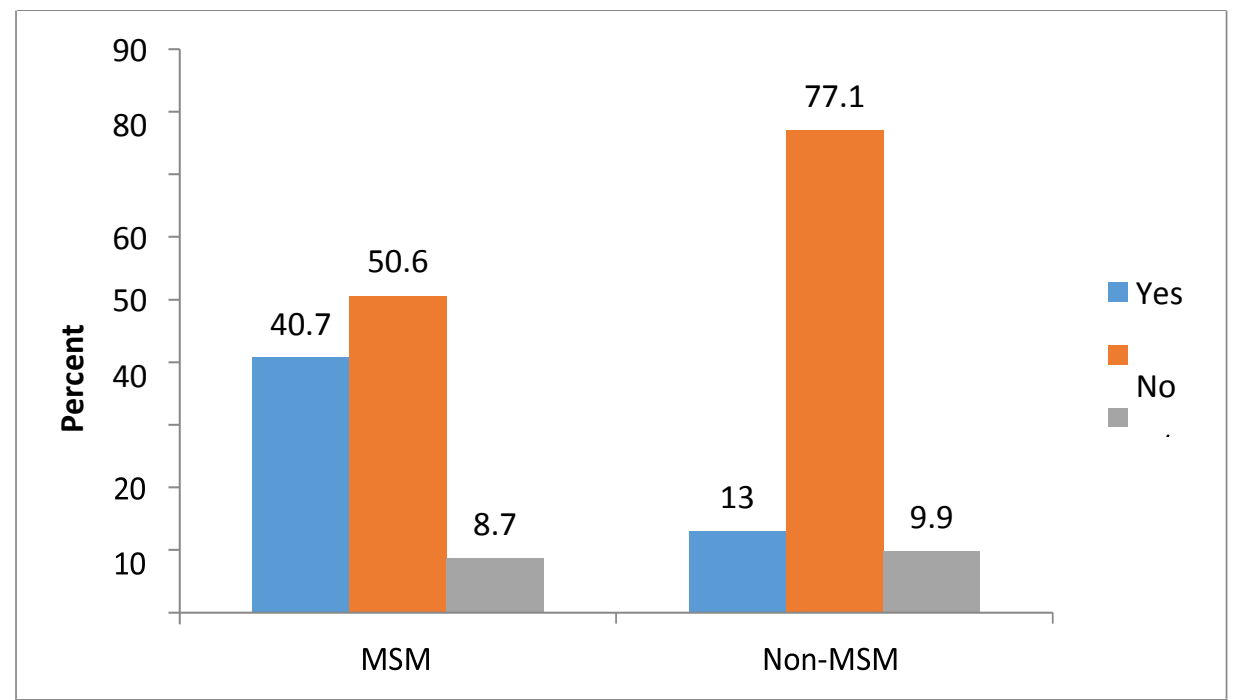

Figure 7: Reported use of lubricant during last penetrative sex act for MSM and non-MSM students 
Table 5: Access to and use of condoms and lubricant

\begin{tabular}{|l|l|c|c|}
\hline \multicolumn{1}{|c|}{ Questions } & \multicolumn{2}{c|}{ MSM } \\
\cline { 2 - 4 } & Possible answers & $\mathbf{n}$ & \% \\
\hline If you used a condom the last time you had sex was it a male or & Male condom & 513 & 98.1 \\
\cline { 2 - 4 } female condom? & Female condom & 10 & 1.9 \\
\hline What brand of condom do you use most of the time? & Choice & 129 & 23.0 \\
\cline { 2 - 4 } & Durex & 160 & 28.5 \\
\cline { 2 - 4 } & Loves Plus & 143 & 25.4 \\
\cline { 2 - 4 } & Trojan & 5 & 0.9 \\
\cline { 2 - 4 } & Other & 125 & 22.2 \\
\hline Did you also use lubricant (the last time you had sex)? & Yes & 290 & 40.7 \\
\cline { 2 - 4 } & No & 360 & 50.6 \\
\cline { 2 - 4 } & Not applicable & 62 & 8.7 \\
\hline Are free condoms available on campus? & Yes & 788 & 87.9 \\
\cline { 2 - 4 } & No & 108 & 12.1 \\
\hline Is free lubricant available on campus? & Yes & 259 & 28.9 \\
\cline { 2 - 4 } & No & 637 & 71.1 \\
\hline How often do you use condoms when you have sex? & All of the time & 254 & 34.3 \\
\cline { 2 - 4 } & Most of the time & 236 & 31.9 \\
\cline { 2 - 4 } & Sometimes & 119 & 16.1 \\
\cline { 2 - 4 } & Rarely & 64 \\
\cline { 2 - 4 } & Never & 67 \\
\hline
\end{tabular}

\section{History of STIs other than HIV and injecting drug use}

In the MSM sample, 14.2 per cent of participants reported having had STIs (other than HIV). However, 19.8 per cent of MSM reported having had genital sores, 9 per cent had experienced a discharge (or unexplained fluid) from the genitals and/or anus, while 26.5 per cent reported a past experience of burning while urinating.

Table 6: History of sexually transmitted infections

\begin{tabular}{|l|l|c|c|}
\hline \multicolumn{1}{|c|}{ Questions } & Possible & \multicolumn{2}{c|}{ MSM } \\
\cline { 2 - 4 } & answers & $\mathbf{n}$ & \% \\
\hline Have you had a sexually transmitted infection (STI)? & Yes & 108 & 14.2 \\
\cline { 2 - 4 } & No & 654 & 85.8 \\
\hline Have you ever had a sore on your penis, testicles, anus or vagina? & Yes & 151 & 19.8 \\
\cline { 2 - 4 } & No & 611 & 80.2 \\
\hline Have you ever had a discharge or unexplained fluid from the genitals or & Yes & 88 & 11.5 \\
\cline { 2 - 4 } anus? & No & 674 & 88.5 \\
\hline Have you ever had burning or pain when you urinated? & Yes & 202 & 26.5 \\
\cline { 2 - 4 } & No & 560 & 73.5 \\
\hline
\end{tabular}

About 2 per cent of MSM participants reported that they or a sex partner had used needles to inject drugs at some point in the past. 
Table 7: Injecting drug use

\begin{tabular}{|c|c|c|c|}
\hline \multirow[b]{2}{*}{ Questions } & \multirow{2}{*}{$\begin{array}{l}\text { Possible } \\
\text { answers }\end{array}$} & \multicolumn{2}{|c|}{ MSM } \\
\hline & & $n$ & $\%$ \\
\hline \multirow[t]{2}{*}{ Have you or your sex partner used needles to inject drugs? } & Yes & 16 & 2.1 \\
\hline & No & 746 & 97.9 \\
\hline
\end{tabular}

\section{Sexual coercion, violence and use of force}

A total of 10.6 per cent of the MSM sample had experienced abuse and/or violence on campus due to their sexual preference $(7.6 \%$ abuse only; $1 \%$ some form of violence; and $2 \%$ both abuse and

violence).

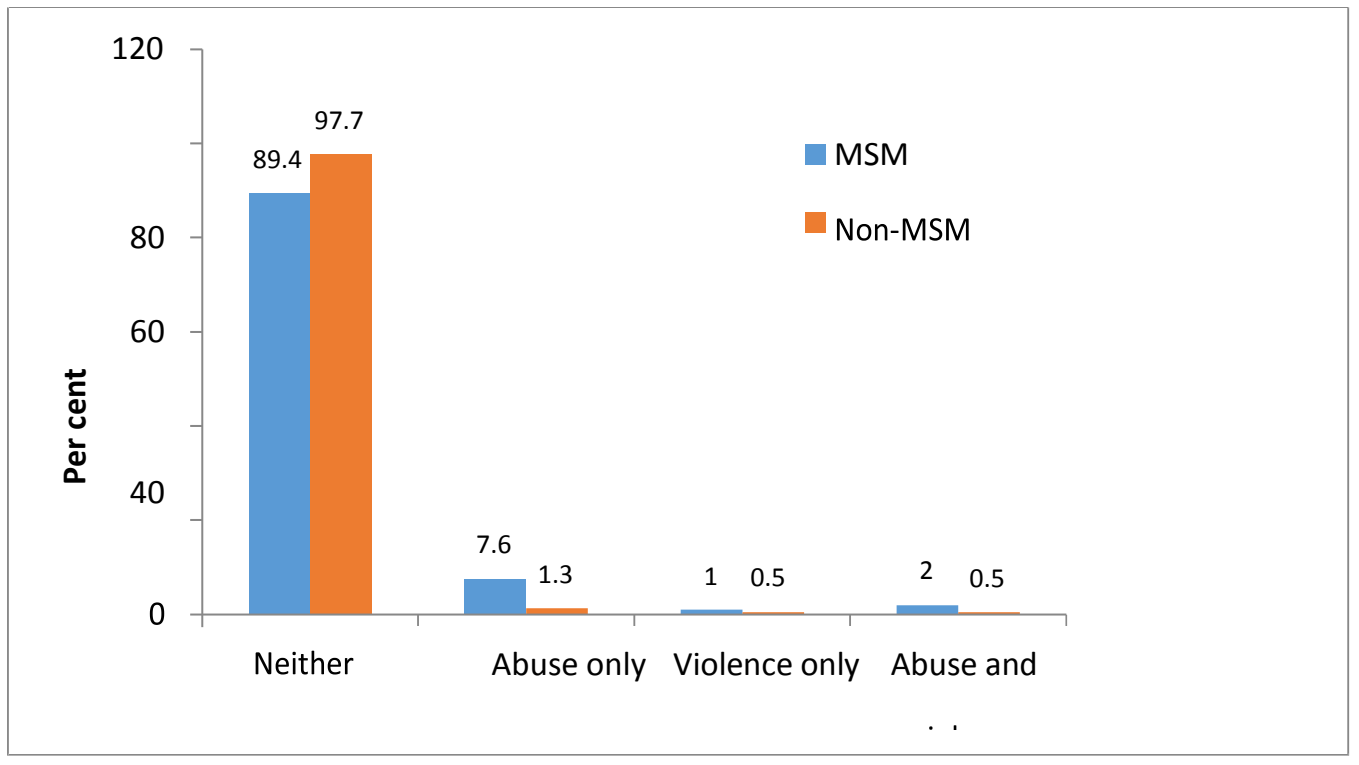

Figure 8: Experience of abuse/violence on campus due to sexual orientation for MSM and non-MSM students

In the MSM sample, 11.8 per cent of participants reported having been forced to have sexual intercourse against their will and 8.9 per cent said they had been hit by a sex partner. In addition, 14.3 per cent of student MSM said they had had sex with someone 'who really did not want (to have sex)' and 3.4 per cent indicated that they had threatened to use force to coerce someone to have sex.

Student MSM reported having accepted material benefits in exchange for sex (5.6\%) and 10.1 per cent said they had offered some benefit in exchange for sex. More than a third (36.4\%) indicated that they had met a sex partner through the internet. The corresponding figure for the non-MSM sample was much lower (8.5\%). 
Table 8: Transactional and coercive sex and violence between partners

\begin{tabular}{|c|c|c|c|}
\hline \multirow[b]{2}{*}{ Questions } & \multirow{2}{*}{$\begin{array}{l}\text { Possible } \\
\text { answers }\end{array}$} & \multicolumn{2}{|c|}{ MSM } \\
\hline & & $\mathbf{n}$ & $\%$ \\
\hline \multirow{2}{*}{$\begin{array}{l}\text { Has someone ever given you money, drugs or a place to stay in exchange for } \\
\text { sex? }\end{array}$} & Yes & 43 & 5.6 \\
\hline & No & 719 & 94.4 \\
\hline \multirow{2}{*}{$\begin{array}{l}\text { Have you ever given someone money, drugs or a place to stay in exchange for } \\
\text { having sex with you? }\end{array}$} & Yes & 77 & 10.1 \\
\hline & No & 685 & 89.9 \\
\hline \multirow[t]{2}{*}{ Have you ever found a sex partner through the internet? } & Yes & 277 & 36.4 \\
\hline & No & 485 & 63.6 \\
\hline \multirow[t]{2}{*}{ Has a sex partner ever hit you? } & Yes & 68 & 8.9 \\
\hline & No & 694 & 91.1 \\
\hline \multirow[t]{2}{*}{ Has someone ever forced you to have sex when you did not want to? } & Yes & 90 & 11.2 \\
\hline & No & 672 & 88.2 \\
\hline \multirow{2}{*}{$\begin{array}{l}\text { Would you be afraid to ask a partner to use condoms because they might hit } \\
\text { you? }\end{array}$} & Yes & 17 & 2.2 \\
\hline & No & 745 & 97.8 \\
\hline \multirow[t]{2}{*}{ Have you ever had sex with someone when they really did not want to? } & Yes & 109 & 14.3 \\
\hline & No & 653 & 85.7 \\
\hline \multirow{2}{*}{$\begin{array}{l}\text { Have you ever threatened to use force to get someone to have sex when they } \\
\text { did not want to? }\end{array}$} & Yes & 26 & 3.4 \\
\hline & No & 736 & 96.6 \\
\hline
\end{tabular}

\section{Alcohol and drug use}

Forty-three percent of the sample of student MSM had moderate to high scores on a multi-item measure of alcohol and drug use compared to 32.5 per cent in the non-MSM sample. Just over one-third of student MSM had a minimal use score and 19.5 per cent fell into the category of no use to low use. The mean score for MSM was $4.72(S D=3.84)$ on a scale ranging from 0 to $>4$, while non-MSM participants had a mean score of $3.83(S D=3.25)$.

Table 9: Summary of alcohol and drug use scores of the sample

\begin{tabular}{|l|c|c|}
\hline & MSM \% & Non-MSM \% \\
\hline No use to low use & 15.5 & 25.1 \\
\hline Minimal use & 37.0 & 42.3 \\
\hline Moderate to high use & 43.4 & 32.5 \\
\hline
\end{tabular}

An analysis confirms that alcohol and drug use scores among student MSM were statistically significantly higher than that of the non-MSM student group ( $U=58.81, p<0.01)$.

One in five student MSM (19.9\%) reported using alcohol and/or drugs the last time they had sex while 52 per cent indicated that they had 'at some point' used alcohol and/or drugs when having sex. Only 1.3 per cent said they always used alcohol and/or drugs when having sex, while 5.1 per cent said they did so 'most of the time' and 18.0 per cent said 'sometimes'. The remaining 27.2 per cent of those who had combined sex and alcohol/drugs had done so rarely. 


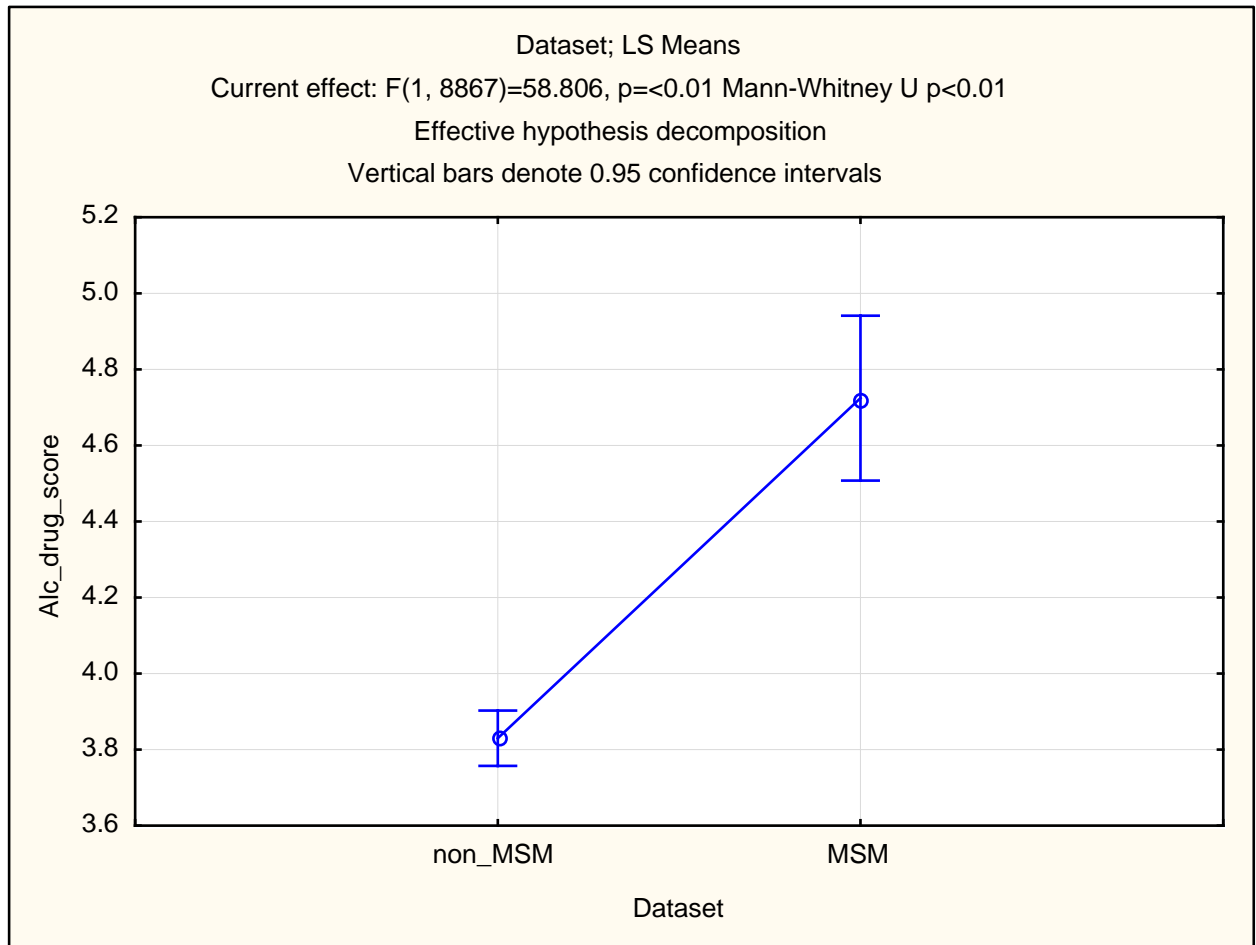

Figure 9: Mann-Whitney test for alcohol and drug use scores

Table 10: Alcohol and/or drug use at last sex of the MSM sample

\begin{tabular}{|l|l|c|c|}
\hline \multicolumn{1}{|c|}{ Questions } & \multicolumn{1}{c|}{$\begin{array}{c}\text { Possible } \\
\text { answers }\end{array}$} & \multicolumn{2}{c|}{ MSM } \\
\hline Did you use alcohol and/or drugs the last time you had sex? & Yes & 152 & 19.9 \\
\cline { 2 - 5 } & No & 610 & 80.1 \\
\hline \multirow{2}{*}{ How often do you use alcohol and/or drugs when you are having sex? } & All of the time & 10 & 1.3 \\
\cline { 2 - 5 } & Most of the time & 39 & 5.1 \\
\cline { 2 - 5 } & Sometimes & 137 & 18.0 \\
\cline { 2 - 5 } & Rarely & 210 & 27.6 \\
\cline { 2 - 4 } & Never & 366 & 48.0 \\
\hline
\end{tabular}

\section{Odds ratios between variables}

The odds of ever having found a sex partner through the internet are 6.15 times greater for MSM compared to non-MSM. This indicates a very strong association between MSM and the risky behaviour of using the internet to search for sex partners. Ever having had an STI are 1.50 times greater for MSM compared to non-MSM, indicating that the association is weak. The odds of alcohol and/or drug use at last sex act are 1.61 times greater for MSM than for non-MSM. This suggests a weak to moderate increase in risk for MSM. The odds of having been forced to have sex are 0.77 times greater for MSM compared to non-MSM, pointing to a weak association. The odds of initiating transactional sex are 2.54 times greater for MSM compared to non-MSM. This is a strong association, suggesting increased risk for MSM. Finally, the likelihood of having threatened to use force against someone in order to obtain sex are 2.30 times greater for MSM. This indicates a moderate to strong association between MSM and coercive sexual behaviour. 
Table 11: Odds ratios for variables: MSM and non-MSM

\begin{tabular}{|l|c|c|c|}
\hline \multicolumn{1}{|c|}{ Variable } & $\begin{array}{c}\text { Odds ratio for } \\
\text { dataset } \\
\text { (MSM : Non- } \\
\text { MSM) }\end{array}$ & \multicolumn{2}{c|}{$\begin{array}{c}\text { 95\% } \\
\text { confidence } \\
\text { interval }\end{array}$} \\
\cline { 2 - 4 } & Lower & Upper \\
\hline Met a sex partner through the internet & 6.155 & 5.163 & 7.338 \\
\hline Ever had an STI & 1.495 & 1.197 & 1.867 \\
\hline Alcohol and/or drug use at last sex & 1.612 & 1.327 & 1.957 \\
\hline Current relationship with a primary partner & 0.631 & .541 & .737 \\
\hline Someone ever forced you to have sex & 0.771 & .611 & .973 \\
\hline $\begin{array}{l}\text { Ever given someone money, drugs or a place to stay in exchange } \\
\text { for having sex with you }\end{array}$ & 2.541 & 1.940 & 3.329 \\
\hline $\begin{array}{l}\text { Ever threatened to use force to get someone to have sex when } \\
\text { they did not want to }\end{array}$ & 2.303 & 1.471 & 3.603 \\
\hline
\end{tabular}

\section{DISCUSSION}

The extent of risky sexual behaviour among the sample of student MSM was consistent with findings of various similar studies involving MSM studying at colleges and universities (Brown and Vanable 2007; Eisenberg 2001; Lindley et al. 2003; So et al. 2005). High turnover of sexual partners and concurrent sexual relationships, which were reflected in this study and in others, have been shown to be part of behavioural patterns that place young MSM at greater risk of contracting HIV (Baral et al. 2007; Van Griensven 2007; UNAIDS 2009).

The MSM in the current study showed some variety in terms of sexual orientation. This indicates the diversity of identities or sexual orientations among men who engage in same-sex behaviour. It also suggests that male students do not necessarily confine their sexual engagements to the dominant pattern for their self-perceived sexual orientation.

Most of the MSM sample had had sexual intercourse. More than half of this sexually experienced group said that they were in a relationship with a primary partner and nearly all of these were having sex with their primary partner. However, in addition to this, a third of sexually experienced MSM said they were having sex with a 'steady' (but not primary) partner and a third with a 'non-steady' partner. Some participants, therefore, were engaging in sex with different categories of partners. Data from this study also showed that some student MSM engaged in (penetrative vaginal) sex with female sex partners.

Experience of anal sex was not confined to the MSM group, but was substantially more common in this sample than among non-MSM.

The study provides strong evidence for multiple concurrent partnerships (MCP) occurring among MSM students and this suggests that more needs to be done to address the HIV transmission risk associated with this behaviour. There is new thinking on the impact of MCPs 
on the spread of HIV which argues that early simulation models showing the network effect of concurrency failed to take into account the coital dilution effect (Sawers and Stillwaggon 2010). Allais and Venter (2012) have argued that there is no single 'concurrency hypothesis' and that the term 'concurrency' is imprecise. The suggestion is that risk lies not so much in the number of partners, but in the nature of the sex act, the relationship and the sexual network. The logical conclusion of such a proposition is that solutions lie not in asking MSM to limit their partners (an approach that may prove ineffective) but in finding ways to make sex safer even within multiplepartner arrangements. An advantage of this alternative approach is that it avoids stigmatising practices that are normal and acceptable within social sub-cultures.

Very few of the student MSM reported having used the female condom. Of those using male condoms many relied on the more freely available complimentary Choice condoms, while many used various commercial brands that generally need to be purchased at stores. About half the MSM group said they used lubricant the last time they had penetrative sex but only a third said that free sachets of lubricant were available on campus. The findings suggest that there is a need to expand lubricant distribution at HEIs and to promote and supply an appropriate version of the female condom for both anal and vaginal sex.

The findings on condom use in this study are in line with findings of other relevant research. In a study in low- and middle-income countries, Baral et al. (2007) found that about half MSM reported using a condom they last time they had anal sex with another man. The Higher Education and Training HIV/AIDS Programme (HEAIDS) national survey of students at HEIs found relatively high condom use among students: 65 per cent of male students aged 18 to 24 years and 60 per cent of those aged 25 years and older reported using a condom the last time they had sex (HEAIDS 2010). An international study of the MSM population at schools and HEIs in many countries showed inconsistent condom use in a context of multiple recent sex partners (Brooks et al. 2008).

Early sexual debut is a risk factor for HIV acquisition (Shisana et al. 2009) and this study showed that a higher proportion of MSM students than non-MSM students first experienced sex at the age of 15 years or younger. The HEAIDS 2010 study found that 73 per cent of South African students at HEIs had had sex before matriculation. The finding of early sexual debut for a section of the MSM sample could indicate a history of sexual abuse in some cases. There is research that has established an association between childhood sexual abuse among MSM and early sexual debut, multiple sex partners and low social support (Bartholow et al. 1994; O’Leary et al. 2003). Transactional sex is also associated with increased risk of HIV transmission.

There was a statistically significant difference between MSM and non-MSM survey 
participants in terms of the use of the internet to meet a sex partner. There is need for additional research to understand how and why so many MSM meet sexual partners online. With the popularity of social applications for men to meet men - such as Badoo, Grindr, Manhant and Gaydar - this trend is likely to be sustained or even grow. It would be important to explore the risks associated with meeting sex partners on the internet as well as the opportunities that applications might offer to enhance support for young MSM and facilitate their access to health services.

Student MSM in this study were more likely to indulge in moderate to heavy consumption of alcohol and drugs than their non-MSM counterparts. In addition to scoring themselves on the alcohol and drug-use scale, participants reported whether they had used alcohol and/or drugs the last time they had sex. Alcohol and drug use in combination with risky sexual behaviour has been linked to an increase in HIV acquisition (Brown and Vanable 2007; So et al. 2005). In a study by Purcell et al. (2001), it was shown that MSM who drank frequently before or during sex were significantly more likely to engage in unprotected sex with casual partners than MSM who did not drink frequently.

A culture of alcohol consumption at universities may expose student MSM to sexual risktaking behaviour. Alcohol reduces the mediating effect that inhibition has on casual sexual encounters (Brown and Vanable 2007). In contrast, the national HEAIDS survey found that students at HEIs who consumed alcohol were significantly less likely to be living with HIV than those who abstained from alcohol (HEAIDS 2010). This same study found that students who reported having been drunk in the previous month were also less likely to have HIV than those who stated they had not been drunk. These findings are counter-intuitive and have not been further researched. However, it is possible that students who are aware they are HIV-positive strive to live healthily and avoid alcohol. It is also possible that students who take alcohol and engage in sex have a heightened awareness of the disease risks they are exposed to and take suitable precautions. The findings warrant further exploration, including their implications for student MSM at HEIs.

Self-reported STIs levels were substantial and responses to questions about some of the signs and symptoms of STIs suggest that an even larger percentage might have been infected with a STI. The presence of STIs other than HIV may increase the risk of acquiring HIV as much as tenfold (Sandfort et al. 2008; Van Dyk 2008). The presence of an STI can create entry points for the HI virus and the immune system response to the STI, involving the direction of large numbers of lymphocytes to the site of infection, creates attachment opportunities for the HI virus (Van Dyk 2008). 
Reported experiences of forced sex is of concern, both in terms having been forced to have sex and those who had threatened to use force to coerce someone to have sex with them. One in ten reported experiencing some form of abuse and/or violence at an HEI based on their sexual orientation. Abuse and violence directed at MSM are based on homophobia, a form of social discrimination featuring 'mean, unfair or unequal treatment intended to marginalise or subordinate individuals or communities based on their real or perceived affiliation with socially constructed stigmatised attributes' (Ayala et al. 2010, 2). Homophobia is often tolerated in communities and this contributes to fear of victimisation and discrimination among MSM populations (UNGASS 2007). Homophobia and discrimination have been shown to be associated with sub-optimal mental health among those groups on the receiving end (Meyer 1995) and may lead to increased self-harm, suicidal thoughts, excessive substance use and risky sexual behaviours among MSM (Mcdermott, Roen and Scourfield 2008; Salomon et al. 2009). In an effort to live their sexual lives covertly, MSM may make unsafe decisions about sex and engage in high risk sexual behaviours. The combination of entrenched homophobia and a history of individual risk-taking may further drive MSM away from health and HIV services (MSMGF 2008).

The odds ratios indicated a set of variables that sexual health programmes for MSM and LGBTQI should focus on when designing evidence-based approaches to intervention. They highlight some of the special features, elevated risks, and special opportunities related to this vulnerable population.

\section{CONCLUSION}

There is a tendency to adopt a 'deficit' approach when investigating same-sex sexualities and sub-cultures. In a sense this study does so by focusing on ways in which gay and other MSM fail to achieve certain public health outcomes and behaviours. The study considered when men fail to use condoms, when they fail to stick to one partner, when they do not go to a clinic and when they experience negative reactions on campus. Perhaps there is a need to invert this negative narrative, asking when MSM do things that contribute to their health and well-being. When do they feel attached to a community? When do student MSM feel heard and understood? When and how do they cope with social and other challenges? How do MSM find intimacy and love in the face of homophobia? How have they found support, connection, services and care on campus? What strengths and survival strategies do they exemplify and bring to their lives? This could be seen as an 'asset' approach. Part of this way of thinking about gay and other MSM is to see them not just as individuals or groups of individuals, but as members of complex and overlapping 
networks and sub-cultures. Membership of these exposes them to and allows them to participate in a web of diverse social spaces and discourses.

This approach is much more interested in the social and structural factors which enable or disable individual decision-making. It would require researchers to view interventions for MSM from a 'total institution' perspective, looking not only at homophobia or the rights of MSM but at the totality of institutional practices and power dynamics as they play out in the halls of teaching and learning, in the curricula, and in the spaces where students live and socialise. This approach challenges the 'either/or' thinking that underpins much HIV prevention work. While risk-reduction strategies do not always work, it makes more sense to build on them than to adopt simple succeed/fail prevention binaries.

Findings of this research - specifically in relation to sexual risk behaviour, and alcohol and drug use, need to be integrated into the current Policy and Strategic Framework on HIV and AIDS for Higher Education (HEAIDS 2012).

There are differences between and within institutions of higher learning which require nuanced, flexible and context-driven interventions which acknowledge both the particularities and commonalities of youth sexualities. Embracing this reality would make sexual health messaging to these groups more sensitive, relevant and sufficiently specific to be of help. Interventions thus grounded would stand a better chance of contributing to a reduction in HIV transmission among student MSM and the creation of enabling environments at South African HEIs.

\section{LIMITATIONS AND RECOMMENDATIONS}

Future research should avoid some of the methodological limitations of the present study. Specifically, larger MSM sample sizes are necessary and must be achieved (despite the fact that many MSM hide their sexual preferences) in order to yield robust data. It may be possible to use respondent-driven sampling techniques to enhance sample size and reach student MSM who were not recruited for this study. In addition, future studies should consider alternative methods to selfselection of participants and data-gathering methods besides online questionnaires.

It might be valuable to undertake longitudinal studies with student MSM - for example, a one-year follow-up study. Adding qualitative components to the research design may afford researchers greater depth of understanding of complex patterns of sexual behaviour among student MSM. These components could include semi-structured interviews and focus group discussions.

Focus areas for future research should include understanding the role of the internet, and 
indeed social media in general, at HEIs and among all emerging sexualities. This technology represents potential for prevention, and should not only be seen as an instrument that facilitates HIV risk behaviours. It is clear that a 'hook-up' culture among MSM exists and will not simply disappear. There is a need for research to explore and understand it better. Questions need to be asked about the relationship between this culture and the decline of social spaces such as clubs and bars - and if the shift represents a disbanding of community or simply a new form of community.

Research and programme development on most-at-risk populations at HEIs (such as student MSM, injecting drug users, students engaging in commercial sex and transgendered students) should be expanded to include additional HEIs in South Africa - and possibly other countries in Africa which experience high HIV prevalence and strong social homophobia.

There is a lack of information about at-risk students attending institutions in the technical and vocational education and training sector. Institutions in this sector should also be included in future research and programme roll out. HEAIDS has been better positioned to lead the above developments since it extended its scope in 2013 to include these institutions. However, it remains important to allow institutions scope to take initiatives that suit their specific situations. HEIs are in a position to develop policy and introduce health promotion interventions to address sexual risk among MSM as well as some of the factors that isolate student MSM, such as discrimination and social homophobia.

Understanding sexual risk behaviours among student MSM may lead to the development and implementation of evidence-based HIV prevention interventions designed to cater to MSM. Failure to respond to these vulnerabilities may lead not only to increased HIV transmission among student MSM, but also to transmission among the broader student population and could impact negatively on the ability of HEIs to fulfil their core mandate.

Rather than viewing inconsistent condom use as an indication that people lack information, willingness, self-efficacy or a self-protective instinct, it might help to frame condom use within a language of intimacy, closeness and desire. Sex is relational and infused with meaning: if we focus on practice only (Kippax 2013) we may be blind to the reality that using (or not using) condoms is imbued with complex meaning - and is not simply a health-seeking behaviour.

There is also a need for HIV programmes to go beyond a mechanistic and reductionist approach to sex, especially in same-sex encounters and relationships. Interventions must recognise the reality of worlds of love, desire, pleasure, mutuality and concern. For example, sex without a condom is not just a negative HIV risk behaviour but also a positive choice for 'pleasure'. In order to address HIV and its attendant risks successfully, these factors must be 
acknowledged in prevention programmes. The gaps and silences in prevention messaging, which tend to reduce gay men and other MSM to hedonistic and anti-social actors, must be filled.

Student MSM at South African HEIs engage in sexual behaviours that place them at increased risk of contracting HIV and other STIs. Understanding the sexual risk behaviours of MSM identified in this study could lead to the development and implementation of evidencebased HIV prevention interventions designed to cater specifically to the sexual health needs of this at-risk group in the student community. Such interventions would also contribute to minimising possible routes for HIV and STI transmission in the wider student population.

\section{ACKNOWLEDGEMENTS}

The following people and/or organisations aided significantly in making this undertaking successful: The staff at HEAIDS: Dr Ramneek Ahluwalia, Programme Director; Ms Managa Pillay, Senior Manager Curriculum and Research; Ms Sinikiwe Sithole, Senior Manager Programmes; Mr Benjamin Janse van Rensburg, Programme Specialist: MSM Programme, NACOSA; Ms Monica du Toit, Prof Martin Kidd and Ms Michelle Munro at Stellenbosch University; Ms Stella Kyobula-Mukoza, HIV/AIDS, Inclusivity and Change Unit (HAICU), University of Cape Town; Ms Zoë Duby, Doctoral Research Fellow, Desmond Tutu HIV Foundation; Dr Andrew Scheibe, Key Populations Consultant; Dr Helen Mavhandu-Mudzusi, Senior Lecturer: Health Studies, University of South Africa; and Mr Pierre Brouard, Co- Director, Centre for Sexualities, AIDS \& Gender, University of Pretoria.

\section{REFERENCES}

Adimora, A. A., V. J. Schoenbach and I. A. Doherty. 2007. Concurrent sexual partnerships among men in the United States. American Journal of Public Health 97: 2230-2237.

Allais, L. and W. Venter. HIV, logic and sex in Africa. Preventive Medicine 55: 401-404.

Ayala, G., J. Beck, K. Lauer, R. Reynolds, R. and M. Sundararaj. 2010. Social discrimination against men who have sex with men: Implications for HIV policy and program. http://www.msmgf.org/ files/msmgf/Advocacy/MSMGF_Social_Discrimination_Poli cy_Brief.pdf.

Baral, S., F. Sifakis, F. Cleghorn and C. Beyrer. 2007. Elevated risk for HIV infection among MSM in low and middle income countries 2000-2006: A systematic review. PLoS Medicine 4: 1901-1911.

Bartholow, B. N., L. S. Doll, D. Joy, J. M. Douglas, G. Bolan, J. S. Harrison, P. M. Moss and David McKirnan. 1994. Emotional, behavioral, and HIV risks associated with sexual abuse among adult homosexual and bisexual men. Child Abuse \& Neglect 18(9): 745-761.

Benotsch, E. G., S. Kalichman and M. Cage. 2001. Men who have met sex partners via the internet: Prevalence, predictors, and implications for HIV prevention. Archives of Sexual Behavior 31: 177183.

Berten, H. and R. Van Rossem. 2009. Doing worse but knowing better: An exploration of the relationship between HIV/AIDS knowledge and sexual behaviour among adolescents in Flemish secondary schools. Journal of Adolescence 32: 1303-1319.

Bolding, G., M. Davis, G. Hart, L. Sherr and J. Elford. 2007. 'Where young MSM meet their first sexual 
partner: The role of the internet.' AIDS Behaviour 11: 522-526. doi: 10.1007/s10461-007-9224-9.

Brooks, R. A., S. Lee, P. A. Newman and A. A. Leibowitz. 2008. Sexual risk behaviour has decreased among men who have sex with men in Los Angeles but remains greater that that among heterosexual men and women. AIDS Education and Prevention 20: 312-324.

Brown, J. L. and P. A. Vanable. 2007. Alcohol use, partner type, and risky sexual behaviour among college students: Findings from an event-level study. Addictive Behaviors 32: 2940-2952. doi: 10.1016/j.addbeh.2007.06.011.

Bryan, A., A. Kagee and M. R. Broaddus. 2006. Condom use among South African adolescents: Developing and testing theoretical models of intention and behaviour. AIDS Behaviour 10: 387397.

CDC. 2007. HIV/AIDS Fact sheet. http://www.cdc.gov/hiv

Cong, L., M. Ono-Kihara, G. Xu, Q. Ma, X. Pan, D. Zhang, T. Homma and M. Kihara. 2008. The characterisation of sexual behaviour in Chinese male university students who have sex with other men: A cross-sectional study. BMC Public Health 8(1): 1.

Dudley, M. G., S. S. Rostosky, B. A. Korfhage and R. S. Zimmerman. 2004. Correlates of high-risk sexual behaviour among young men who have sex with men. AIDS Education and Prevention 16: 328340.

Eisenberg, M. 2001. Differences in sexual risk behaviours between college students with same-sex and opposite-sex experience: Results from a national survey. Archives of Sexual Behaviour 30: 575589.

Faulkner, A. H. and K. Cranston. 1998. Correlates of same-sex sexual behaviour in a random sample of Massachusetts high school students. American Journal of Public Health 88: 262-266.

Hart, G. J. and J. Elford. 2010. Sexual risk behaviour of men who have sex with men: Emerging patterns and new challenges. Current Opinion in Infectious Diseases 23: 39-44.

HEAIDS. 2010. HIV Prevalence and related factors - Higher education sector study, South Africa, 2008-2009. Pretoria: Higher Education South Africa.

HEAIDS. 2012. Policy and Strategic Framework on HIV and AIDS for Higher Education. Pretoria: Higher Education HIV/AIDS Programme.

Kippax, S. 2013. Between individual agency and structure in HIV prevention: Understanding the middle ground of social practice. American Journal of Public Health. http://ajph.aphapublications. org/doi/abs/10.2105/AJPH.2013.301301

Lindley, L. L., T. J. Nicholson, M. B. Kerby and N. Lu. 2003. HIV/STI associated risk behaviours among self-identified lesbian, gay, bisexual, and transgender college students in the United States. AIDS Education and Prevention 15(5): 413-425.

MacKellar, D., L. Valleroy, J. Karon, G. Lemp and R. Janssen. 1996. The young men's survey: Methods for estimating HIV seroprevalence and risk factors among young men who have sex with men. Public Health Reports 111: 138-144.

Mcdermott, E., K. Roen and J. Scourfield. 2008. Avoiding shame: LGBT people, homophobia and selfdestructive behaviours. Culture Health \& Sexuality 10: 815-829.

Meyer, I. H. 1995. Minority stress and mental health in gay men. Journal of Health and Social Behaviour 36(1): 38-56.

MSMGF. 2008. MSM, HIV and the road to universal access: How far have we come? http://www. amfar.org/uploadedFiles/In_the_Community/Publications/MSM\%20HIV \%20and\%20the\%20 Road\%20to\%20Universal\%20Access.pdf

Murray, S. O. and W. Roscoe. (Eds). 1998. Boy-wives and female husbands: Studies of African homosexualities. New York, NY: Palgrave.

O’Leary, A., D. Purcell, R. H. Remein and C. Gomez. 2003. Childhood sexual abuse and sexual transmission risk behaviour among HIV-positive men who have sex with men. AIDS Care 15: 1726. 
Purcell, D. W., J. T. Parsons, P. N. Halkitis, J. Mizuno and W. J. Woods 2001. Substance use and sexual transmission risk behavior of HIV-positive men who have sex with men. Journal of Substance Abuse 13(1): 185-200. doi: 10.1016/S0899-3289(01)00072-4.

Salomon, E. A., M. J. Mimiaga, M. J. Husnik, S. L. Welles, M. W. Manseau, A. B. Montenegro, S. A. Safren, B. A. Koblin, M. A. Chesney and K. H. Mayer. 2009. Depressive symptoms, utilization of mental health care, substance use and sexual risk among young men who have sex with men in EXPLORE: Implications for age-specific interventions. AIDS and Behavior 13(4): 811-821.

Sandfort, T. G. M., J. Nel, E. Rich V. Reddy and H. Yi. 2008. HIV testing and self-reported HIV status in South African men who have sex with men: Results from a community-based survey. Sexually Transmitted Infections 84: 425-429.

Sawers, L. and E. Stillwaggon. 2010. Concurrent sexual partnerships do not explain the HIV epidemics in Africa: A systematic review of the evidence. Journal of the International AIDS Society: 13: 34.

Shisana, O., T. Rehle, L. C. Simbayi, K. Zuma and S. Jooste. 2009. South African national HIV prevalence incidence behaviour and communication survey 2008: A turning tide among teenagers? Cape Town: HSRC Press.

So, D. W., F. Y. Wong and J. M. DeLeon. 2005. Sex, HIV risks, and substance use among Asian American college students. Aids Education and Prevention 17: 457-468.

Tung, W., K. Ding and S. Farmer. 2008. Knowledge, attitude, and behaviours related to HIV and AIDS among college students in Taiwan. Journal of the Association of Nurses in AIDS Care 19: 397-408. doi: 10.1016/j.jana.2008.04.009.

UNAIDS. 2009. Report on the global AIDS epidemic. Geneva: UNAIDS.

UNGASS. 2007. UNAIDS Annual report: Knowing your epidemic. http://www.unaids.org/en/media/ unaids/contentassets/dataimport/pub/report/2008/ jc1535_annual_report07_en.pdf

Van Dyk, A. 2008. HIV/AIDS care \& counselling: A multidisciplinary approach. Cape Town: Pearson Education.

Van Griensven, F. 2007. Men who have sex with men and their HIV epidemics in Africa. AIDS 21: 13611362.

Warren, J. C., M. I. Fernández, G. W. Harper, M. A. Hidalgo, O. B. Jamil and R. S. Torres. 2008. Predictors of unprotected sex among young sexually active African American, Hispanic, and White MSM: The importance of ethnicity and culture. AIDS Behaviour 12: 459-468.

WHO. 2004. Rapid assessment and response adaptation guide on HIV and men who have sex with men. Geneva: WHO.

Winters, K. C. and J. M. Zenilman. 1994. Simple screening instruments for outreach for alcohol and other drug abuse and infectious diseases (Vol. 11). US Department of Health and Human Services, Public Health Service, Substance Abuse and Mental Health Services Administration, Center for Substance Abuse Treatment. 